\title{
Respiradores elastoméricos: una alternativa en tiempos de pandemia COVID 19
}

\section{Elastomeric respirators: an alternative in times of pandemic COVID 19}

\author{
Jorge Chachaima-Mar ${ }^{1,2, a}$, Jesus Pérez-Castilla ${ }^{3, b}$ \\ 1 Facultad de Medicina, Universidad Peruana Cayetano Heredia, Lima, Perú. \\ ${ }^{2}$ Red de Eficacia Clínica y Sanitaria, REDECS. Lima, Perú. \\ ${ }^{3}$ Facultad de Medicina, Universidad Nacional San Antonio Abad del Cusco. Cusco, Perú. \\ ${ }^{a}$ Estudiante de medicina \\ ${ }^{\mathrm{b}}$ Médico cirujano
}

Correspondencia:

Jorge Emerson Chachaima Mar

jorge.chachaima@upch.pe

Recibido: 13 de mayo 2020

Aprobado: 26 de mayo 2020

Publicación en línea: 27 de mayo 2020

Conflictos de interés: Los autores declaran no tener conflictos de interés.

Fuente de financiamiento:

Autofinanciado

Citar como: Chachaima-Mar J, PérezCastilla J. Respiradores elastoméricos: una alternativa en tiempos de pandemia COVID 19. An Fac med. 2020;81(2):254-5. DOI: https://doi. org/10.15381/anales.v81i2.17801
An Fac med. 2020;81(2):254-5. / DOI: https://doi.org/10.15381/anales.v81i2.17801

Sr. Editor,

En la actualidad nos encontramos en una pandemia generada por el SARS-CoV 2, un virus que en poco tiempo se expandió por todos los continentes. En este escenario, es vital que el personal de salud se proteja de la forma más eficiente posible, pues ellos son los que se encargan de librar la lucha contra esta patógeno. Sin embargo, una parte esencial del equipo de protección personal-los respiradores N95- ha comenzado a escasear en los países más golpeados por la pandemia ${ }^{(1)}$. Una alternativa factible a los respiradores N95 son los respiradores elastoméricos ${ }^{(2)}$. No obstante, esta alternativa no es mencionada en los documentos técnicos de muchos países latinoamericanos ${ }^{(3,4)}$ ni es mencionada por la Organización Panamericana de la Salud en sus recomendaciones para el equipo de protección personal ${ }^{(5)}$. Es por ello que presentamos las principales características de los respiradores elastoméricos en relación a los respiradores N95.

Los respiradores elastoméricos son fabricados de material sintético a comparación del propileno que se utiliza en los respiradores N95 (2). Gracias al material que componen, los respiradores elastoméricos pueden ser fácilmente reusados y no alteran su forma con el reuso. Además, la limpieza se puede realizar fácilmente con productos desinfectantes, pero aún no se tiene muy claro los protocolos de desinfección que se deberían utilizar para los respiradores elastoméricos en áreas de cuidado de la salud ${ }^{(2)}$. En cambio, los respiradores N95 no están acondicionados para ser reutilizados, pues pueden perder su forma y disminuir la eficiencia en el filtrado de partículas. En cuanto a la protección que ambos ofrecen, los respiradores elastoméricos pueden proteger al usuario frente a material peligroso con una eficacia similar o superior al de un respirador N95 siendo efectivo contra virus respiratorios tales como influenza ${ }^{(6)}$ (Figura 1).

En la tabla 1 se muestran las ventajas y desventajas de los respiradores elastoméricos y respiradores desechables (N95 y FFP2). Ambos, tanto el respirador elastomérico y el respirador N95, necesitan una prueba de ajuste para poder utilizarse de manera adecuada. A pesar de que el costo de los respiradores elastoméricos es una de sus desventajas, signifi- 
Tabla 1. Ventajas y desventajas de los respiradores elastoméricos y respiradores desechables (N95 y FFP2).

\begin{tabular}{|c|c|c|}
\hline & Respiradores elastoméricos & Respiradores desechables (N95 y FFP2) \\
\hline Ventajas & $\begin{array}{ll}\text { - } \quad \text { Puede reutilizarse } \\
\text { - } \quad \text { No pierde la forma después } \\
\text { de varios usos } \\
\text { - Eficiencia similar o superior a } \\
\text { un respirador N95 }\end{array}$ & $\begin{array}{ll}\text { - } & \text { Menor costo } \\
\text { - } \quad \text { Liviano y de dimensiones } \\
\text { pequeñas } \\
\text { - } \quad \text { Portable }\end{array}$ \\
\hline Desventajas & $\begin{array}{ll}\text { - } & \text { Costo elevado } \\
\text { - } & \text { Grandes dimensiones y peso } \\
\text { elevado } \\
\text { - } \quad \text { Problemas físicos y } \\
\text { psicológicos } \\
\text { - } \quad \text { Interferencia en la } \\
\text { interacción con el paciente }\end{array}$ & $\begin{array}{l}\text { - } \quad \text { Causa molestias psicológicas } \\
\text { - } \quad \text { No reutilizable* }\end{array}$ \\
\hline
\end{tabular}

* Existen ciertas condiciones especiales que se tienen que cumplir para que puedan ser reutilizadas

cativamente mayor al de los respiradores N95, se considera que su uso es costo efectivo ya que el personal de salud usa varios respiradores desechables durante un corto periodo de tiempo ${ }^{(2)}$

Finalmente, las mascarillas ideales deben ser cómodas para su uso por personal de salud y no deben interrumpir la interacción de estos últimos con los pacientes. Por su parte, los respiradores

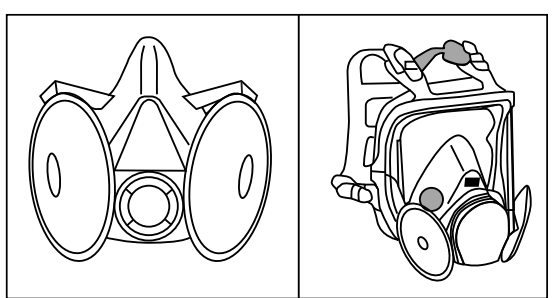

Figura 1. Tipos de respiradores elastoméricos de máscara media y completa ${ }^{(6)}$. elastoméricos suelen tener un mayor peso y volumen, lo que puede ocasionar molestias diversas: molestias tanto al ser llevado por el personal de salud, al usarse pues limitan la visión y distorsionan la voz del usuario dificultando la comunicación con el paciente ${ }^{(2)}$. Además, estas pueden causar molestias físicas y psicológicas tales como irritación de la piel y ansiedad en el usuario ${ }^{(2)}$. Por otro lado, las mascarillas N95 han sido utilizadas por el personal de salud por su comodidad y dimensiones pequeñas que lo hacen portable; pero estas mascarillas no están exentas de molestias, pues también pueden causar molestias subjetivas de discomfort en los usuarios ${ }^{(7)}$.

\section{REFERENCIA BIBLIOGRÁFICAS}

1. The New York Times [Internet]. Goodnough A. Some Hospitals Are Close to Running Out of Crucial Masks for Coronavirus, 2020 Mar 9 [Fecha de acceso: 29 de marzo 2020]. Disponible en: https://www. nytimes.com/2020/03/09/health/coronavirus-n95face-masks.html

2. National Academies of Sciences, Engineering, and Medicine, Health and Medicine Division, Board on Health Sciences Policy, Committee on the Use of Elastomeric Respirators in Health Care, Liverman CT, Yost OC, et al. Elastomeric Respirators. National Academies Press (US); 2018.

3. División de Prevención y Control de Enfermedades. Recomendaciones Clínicas basadas en Evidencia COVID-19 [Internet]. Chile [Fecha de acceso: 14 de abril 2020]. Disponible en: https://diprece.minsal. cl/temas-de-salud/temas-de-salud/guias-clinicasno-ges/guias-clinicas-no-ges-enfermedadestransmisibles/covid-19/recomendaciones/

4. Plataforma digital única del Estado Peruano [Internet]. Prevención, diagnóstico y tratamiento de personas afectadas por COVID-19 en el Perú y modifcatorias. Perú: Ministerio de Salud 2020 [Fecha de acceso: 10 de mayo 2020]. Disponible en: https://www.gob.pe/institucion/minsa/informespublicaciones/473587-prevencion-diagnosticoy-tratamiento-de-personas-afectadas-por-covid19-en-el-peru

5. Requerimientos para uso de equipos de protección personal (EPP) para el nuevo coronavirus (2019-nCoV) en establecimientos de salud [Internet]. Organización Panamericana de la Salud [Fecha de acceso: 6 de febrero 2020]. Disponible en: https://iris.paho.org/bitstream/ handle/10665.2/51905/requirements-\%20PPEcoronavirus-spa.pdf? sequence $=1$ \&isAllowed $=y$

6. Pandemic Influenza Preparedness Planning: Practical Considerations for Respirator Use in a Health Care Setting [Internet]. 3M; 2017 [Fecha de acceso: 6 de febrero 2020]. Disponible en: http:// multimedia.3m.com/mws/media/437992O/tdbpandemic-influenza-preparedness-planning.pdf

7. Li Y, Tokura H, Guo YP, Wong ASW, Wong T, Chung J, et al. Effects of wearing N95 and surgical facemasks on heart rate, thermal stress and subjective sensations. Int Arch Occup Environ Health. 2005;78(6):501-9. DOI: 10.1007/s00420-004-0584-4 